\title{
Cognitive Deficits as a Mediator of Poor Occupational Function in Remitted Major Depressive Disorder Patients
}

\author{
Young Sup Woo ${ }^{1,2}$, Joshua D. Rosenblat, ${ }^{1,3}$, Ron Kakar ${ }^{1,4}$, Won-Myong Bahk ${ }^{2}$, Roger S. Mclntyre ${ }^{1,3}$ \\ ${ }^{1}$ Mood Disorders Psychopharmacology Unit, University Health Network, Toronto, Ontario, Canada, ${ }^{2}$ Department of Psychiatry, College of \\ Medicine, The Catholic University of Korea, Seoul, Korea, ${ }^{3}$ Department of Psychiatry, University of Toronto, Toronto, ${ }^{4}$ Department of \\ Psychiatry, Western University, London, Ontario, Canada
}

\begin{abstract}
Cognitive deficits in major depressive disorder (MDD) patients have been described in numerous studies. However, few reports have aimed to describe cognitive deficits in the remitted state of MDD and the mediational effect of cognitive deficits on occupational outcome. The aim of the current review is to synthesize the literature on the mediating and moderating effects of specific domains of cognition on occupational impairment among people with remitted MDD. In addition, predictors of cognitive deficits found to be vocationally important will be examined. Upon examination of the extant literature, attention, executive function and verbal memory are areas of consistent impairment in remitted MDD patients. Cognitive domains shown to have considerable impact on vocational functioning include deficits in memory, attention, learning and executive function. Factors that adversely affect cognitive function related to occupational accommodation include higher age, late age at onset, residual depressive symptoms, history of melancholic/psychotic depression, and physical/psychiatric comorbidity, whereas higher levels of education showed a protective effect against cognitive deficit. Cognitive deficits are a principal mediator of occupational impairment in remitted MDD patients. Therapeutic interventions specifically targeting cognitive deficits in MDD are needed, even in the remitted state, to improve functional recovery, especially in patients who have a higher risk of cognitive deficit.
\end{abstract}

KEY WORDS: Depression; Remission; Cognition; Occupational outcome.

\section{INTRODUCTION}

Major depressive disorder (MDD) is a chronic mental disorder with a lifetime prevalence of 5-20\%. ${ }^{1,2)}$ MDD is associated with functional impairment both at home and in the workplace, significantly and chronically reducing quality of life. ${ }^{3-5)}$ Further, MDD has been found to be the fourth leading contributor to disease burden worldwide ${ }^{6}$ and is predicted to the second leading cause of disability adjusted life-years in 2020 and the leading cause of disability adjusted life-years in 2030 according to the Global Burden of Disease Study. ${ }^{7,8)}$

Functional impairment in MDD patients is attributable several factors including but not limited to mood disturbances, cognitive dysfunction, lack of energy and motivation, psychomotor retardation, fatigue, and insomnia.

\footnotetext{
Received: May 13, 2015 / Revised: July 21, 2015

Accepted: August 26, 2015

Address for correspondence: Roger S. Mclntyre, MD, FRCPC Mood Disorders Psychopharmacology Unit, University Health Network, 399 Bathurst Street, Toronto, Ontario, M5T 2S8, Canada Tel: +1-416-603-5279, Fax: +1-416-603-5279 E-mail: Roger.Mclntyre@uhn.ca
}

The severity of functional impairment in MDD patients was significantly correlated to the severity of depressive symptoms. Judd et al. ${ }^{9)}$ reported that with each increasing level of depressive symptom severity, impairments in global function, as well as function at work and at home, was significantly increased.

Of note, even milder forms of the disorder, such as minor depression, dysthymia, or subthreshold depressive symptomatology can significantly affect function. ${ }^{9-12)}$ Further, functional impairment is not restricted to mood episodes; similar levels of impairment have been noted during periods of remission. ${ }^{13)}$ Indeed, symptom improvement is a poor predictor of functional improvement and work loss. ${ }^{13,14)}$

Of the functional domains affected by MDD (work, household duties or schoolwork), the most disrupted was, work impairment; severe impairment was observed during a considerable portion of the follow-up period (20-30\% of months). ${ }^{15)}$ Also in a study with US workers, a significant component of the overall disability and cost associated with depression relates to impaired workplace performance. $^{16)}$

(c) This is an Open-Access article distributed under the terms of the Creative Commons Attribution Non-Commercial License (http://creativecommons.org/licenses/by-nc/4.0) which permits unrestricted non-commercial use, distribution, and reproduction in any medium, provided the original work is properly cited. 
Cognitive deficits associated with MDD may be a key factor affecting patients' ability to function in the workplace. ${ }^{17,18)}$ A broad range of cognitive processes including attention, decision-making, problem solving, language, and memory are strongly affected in MDD. Cognitive impairment has been widely reported in patients during episodes of major depression. ${ }^{19,20)}$ Further, cognitive deficits can still be detected in periods of remission ${ }^{21)}$ and significantly affect the individual's social and occupational function. ${ }^{22)}$ Indeed, meta-analyses have shown that cognitive deficits are still present in remitted patients. ${ }^{23,24)}$ Moreover, persistent cognitive dysfunction has been shown to be a key mediating factor of impaired occupational function. In a large, cross-sectional study with data from the European Study of the Epidemiology of Mental Disorders (ESEMeD) including 21,425 adults from six European countries, ${ }^{25)}$ only two factors, including cognitive dysfunction and embarrassment, mediated the association between depression and role functioning. In this study, role functioning was evaluated with ESEMeD and World Health Organization Disability Assessment Scale (ESEMeD-WHODAS) which assessed work functioning at home and in paid employment. Taken together, cognitive dysfunction may be a significant mediating factor of the functional impairment in the workplace observed in MDD patients during mood episodes as well as during periods of remission.

Impairment in the workplace is often of great concern for patients, clinicians and employers alike. However, in MDD, treatment and prognostication of workplace disability is often complex and uncertain. Therefore, the aim of the current review is to describe the role of cognitive impairment in functional outcome after remission from MDD, especially targeted at work functioning. Toward this aim, we review (1) cognitive deficits in remitted MDD patients, (2) the effect of cognitive deficits on occupational functional outcome, and (3) predictors of cognitive deficits which related to poor occupational functional outcome after remission.

\section{MAIN SUBJECTS}

\section{Search Methods and Selection Criteria}

To identify studies on relationship between occupational outcome and cognitive function, we performed a comprehensive literature search using Medline and EMBASE. The search term were as follows; (employ* or occupation* or vocation* or function* or job or cognitive function or cognition) and (depression or depressive) and (remission or remitted or euthymic). We did not filter papers by age/gender or other demographic characteristics. The abstracts and titles of articles retrieved were reviewed to identify relevant papers. Selected articles were then reviewed and only articles written in English and investigated the relationships between more than two among depression, cognitive function or occupational function were included. Studies with only patients with bipolar depression or symptomatic depression were excluded. In addition, reference lists of selected articles were searched to identify additional references.

\section{Cognitive Function in Depressed Patients during Periods of Remission}

Several cognitive domains, including memory, attention, processing speed, and executive function, have been investigated during periods of remission (Table 1). In 2000 , Reischies and $\mathrm{Neu}^{26)}$ studied the degree of reversibility of cognitive dysfunction in depression. In their depressed state, the patients performed poorly in most neuropsychological tests, and about one third of MDD patients performed at an impaired level in tests of averbal memory and verbal fluency. In their remitted state, there was no normalization of cognitive test performance including verbal/visual memory and visual-motor sequencing, in spite of complete recovery of the affective symptoms. These results were in keeping with previous results, which reported impaired visual-motor sequencing and memory in euthymic patients with a history of chronic MDD. ${ }^{27)}$ Neu et l. $^{28)}$ included 27 MDD patients and assessed them with neuropsychological tests at the beginning of the depressive episode and during a period of euthymia. At the onset of a depressive episode, patients performed significantly worse than the healthy controls in all tests including Rey Auditory Learning Test, Reitan Trail Making Test A, verbal fluency test and Wechsler Memory Scale (visual memory index). After sustained remission, the patient group still performed significantly worse in verbal memory and verbal fluency compared to healthy controls. A longitudinal study also reported impaired visual memory. ${ }^{29)}$ In a recent study with 97 remitted patients and 97 healthy controls, patients with remitted MDD were impaired on verbal memory when compared to control. ${ }^{30)}$ However, in a longitudinal analysis of neurocognitive function in MDD patients, ${ }^{29)}$ remission of depression was followed by improvement in verbal memory function up to the level of healthy controls. Verbal learning, delayed recall, and recognition were unimpaired in another study with euthymic MDD patients. ${ }^{31)}$ In young, euthymic pa- 
Table 1. Impaired cognitive domains in remitted major depressive disorder patients

\begin{tabular}{|c|c|c|}
\hline Study & Cognitive test performed & Cognitive domains impaired \\
\hline Beats et $a .^{44)}$ & CANTAB & $\begin{array}{l}\text { No significant difference between patients and healthy } \\
\text { controls }\end{array}$ \\
\hline Kessing $^{121)}$ & $\begin{array}{l}\text { Cambridge Cognitive Examination, Mattis Dementia } \\
\text { Rating Scale, Gottfries-Bråne-Steen Dementia Rating } \\
\text { Scale, Mini-Mental State Examination, Global Deterio- } \\
\text { ration Scale }\end{array}$ & Patients significantly impaired on all tests \\
\hline $\begin{array}{l}\text { Weiland-Fiedler } \\
\text { et } a l^{34)}\end{array}$ & CANTAB & $\begin{array}{l}\text { Patients significantly impaired on attention and working } \\
\text { memory }\end{array}$ \\
\hline Clark et $a l^{31,37)}$ & $\begin{array}{l}\text { Rapid visual information processing task, CVLT, and the } \\
\text { intra-dimensional/extra-dimensional shift task of the } \\
\text { CANTAB }\end{array}$ & $\begin{array}{l}\text { No significant difference between patients and healthy } \\
\text { controls }^{37)} \\
\text { Patients impaired on executive function }\end{array}$ \\
\hline Neu et $a l^{28)}$ & $\begin{array}{l}\text { RAVLT, Trail-Making Test (part A), verbal fluency test } \\
\text { (animal naming), Wechsler memory subscale (visual } \\
\text { memory) }\end{array}$ & $\begin{array}{l}\text { Patients significantly impaired on the verbal memory } \\
\text { and fluency }\end{array}$ \\
\hline $\begin{array}{l}\text { Paelecke-Habermann } \\
\text { et } a l .^{35)}\end{array}$ & $\begin{array}{l}\text { Visual orienting task (computerized test), sustained } \\
\text { attention task (card sorting task), executive attention, } \\
\text { behavioral assessment of the dysexecutive syndrome } \\
\text { test }\end{array}$ & $\begin{array}{l}\text { Patients significantly impaired on attentional and ex- } \\
\text { ecutive functions }\end{array}$ \\
\hline Smith et $a l^{32)}$ & $\begin{array}{l}\text { CVLT, Brixton spatial anticipation Test, Trail Making Test } \\
\text { (part A and B), Stroop Color Word }\end{array}$ & $\begin{array}{l}\text { Patients significantly impaired on trials verbal learning, } \\
\text { attention, and executive function }\end{array}$ \\
\hline Biringer et al. $^{29)}$ & $\begin{array}{l}\text { Stroop Color, Stroop Word, Stroop Color Word, WCST } \\
\text { perseverative responses, and California Computer- } \\
\text { ized Assessment Package simple reaction time }\end{array}$ & $\begin{array}{l}\text { No significant difference between patients and healthy } \\
\text { controls }\end{array}$ \\
\hline Yuan et $a .^{39)}$ & $\begin{array}{l}\text { RAVLT, Trail Making Test (part A and B), Clock drawing } \\
\text { test, Digit Span test }\end{array}$ & $\begin{array}{l}\text { Patients significantly impaired on verbal learning, at- } \\
\text { tention and executive function }\end{array}$ \\
\hline Nakano et $a l^{38)}$ & WCST, Stroop test and verbal fluency test & Patients significantly impaired on executive function \\
\hline Preiss et $a l^{30)}$ & $\begin{array}{l}\text { Auditory Verbal Learning Test, Trail Making Test (part A } \\
\text { and B) }\end{array}$ & $\begin{array}{l}\text { Patients significantly impaired on verbal learning and } \\
\text { attention }\end{array}$ \\
\hline Hasselbalch et $a l^{42)}$ & $\begin{array}{l}\text { Trail Making Test (part A and B), Symbol Digit Modal- } \\
\text { ities Test, RAVLT, modified version of Category Cued } \\
\text { Recall, Rey-Osterrieth Complex Figure Test, Familiar } \\
\text { Faces, Boston Naming Test, verbal fluency test (pho- } \\
\text { nological and semantic), Stroop test, WCST, Letter- } \\
\text { Number Sequencing }\end{array}$ & $\begin{array}{l}\text { Patients significantly impaired on attention and ex- } \\
\text { ecutive function }\end{array}$ \\
\hline Daniel et $a l^{33)}$ & $\begin{array}{l}\text { Babcock Story Recall Test, WCST, Trail Making Test (part } \\
\text { B), Stroop Color Word Test, Symbol-Number Associa- } \\
\text { tion Test from WAIS-R, Digit Span from WAIS-R }\end{array}$ & $\begin{array}{l}\text { Patients significantly impaired on executive function } \\
\text { and attention }\end{array}$ \\
\hline
\end{tabular}

CANTAB, Cambridge Automated Neuropsychological Test Battery; WCST, Wisconsin Card Sorting Test; CVLT, California Verbal Learning Test; RAVLT, Rey Auditory Verbal Learning Test; WAIS-R, Wechsler Adult Intelligence Scale-Revised.

tients with MDD, verbal memory was not significantly impaired from controls. ${ }^{32)}$ A recent study investigated differences in neurocognitive performance between groups of euthymic patients with a history of MDD or bipolar I disorder and a healthy control group. It was noted that verbal memory was not significantly different between control and MDD or bipolar I disorder patients. ${ }^{33)}$

Some authors reported impairment in remitted depressed patients on attention as well. Weiland-Fiedler et $a l .{ }^{34)}$ described the neuropsychological functioning of fully remitted, unmedicated patients with a history of MDD. When compared between 28 young to middleaged, unmedicated, fully remitted patients with MDD to 23 healthy control subjects, patients were impaired on tasks of rapid visual information processing, psychomotor performance and spatial working memory relative to controls. After correction for residual depressive symptoms, deficits in sustained attention remained significant and more subtle deficits were found in the mnemonic and strategic aspects of working memory. The authors suggested ongoing deficits in sustained attention as vulnerability marker for MDD. In another study including $40 \mathrm{eu}-$ thymic MDD patients and 20 healthy controls, ${ }^{35)}$ euthymic patients with MDD showed deficits in all tests related to attention (attentional shift, Stroop task, sustained attention) compared to healthy controls. Deficits in attention, visual memory, psychomotor speed, and working memory were also reported in a longitudinal study. ${ }^{29)}$ Euthymic MDD patients showed deficits in attentional set shifting, as well. They were more likely to fail the intra-dimensional/extra-dimensional shift task than the healthy comparison subjects ${ }^{31,36)}$ and attention assessed with Trail 
Making Test A. ${ }^{30)}$ However, the impairment in sustained attention in remitted MDD patients was not replicated on an independent sample of 15 remitted MDD patients. ${ }^{37)}$ Sustained attention deficit was confirmed only in the euthymic bipolar patients. These results are also inconsistent when compared to a recent study, which investigated differences in neurocognitive performance between groups of patients with MDD or bipolar I disorder in a euthymic state and a healthy control group. In this study, patients demonstrated reduced performance on attention/working memory ${ }^{33)}$ compared with healthy controls. Performance on neurocognitive tasks did not differ between patients with MDD versus bipolar I disorder.

Executive function was another cognitive domain reported as impaired in remitted MDD patients. PaeleckeHabermann et al. ${ }^{35)}$ showed that euthymic patients with MDD exhibited deficits in executive functions (behavioural assessment of the dysexecutive syndrome, word fluency, memory span) compared to healthy controls. In another study which included 79 remitted MDD patients and 85 healthy controls, ${ }^{38)}$ the remitted MDD group showed significantly poorer performance on Stroop test. The elderly MDD group showed significantly lower scores for verbal fluency test than the control group and the young MDD group. Impaired executive function in remitted MDD was further supported by Yuan et al., ${ }^{39)}$ who examined the relationship between neuropsychological deficits and brain regional activity in elderly remitted MDD patients. They reported significantly worse performance on the delayed recall of Rey Auditory Verbal Learning Test and executive function (Trail Making Test A and B) in the MDD group when compared with the control group. Impairment in executive function was reported in several studies. ${ }^{26,27,30,32)}$ Daniel et al. ${ }^{33)}$ recently reported deficits in executive function in patients with remitted MDD or bipolar I disorder when compared to healthy controls. Lin et $a l .{ }^{40)}$ compared remitted MDD patients with melancholic, atypical, or undifferentiated type with healthy controls. Attention and executive function were impaired in melancholic and undifferentiated types of MDD compared to healthy controls. Verbal fluency was impaired in melancholic MDD. Conversely, Biringer et al. ${ }^{41)}$ reported returning of executive function to normal levels accompanied with remission. They found an improvement in executive functions in young depressive patients in remission (both medicated and non-medicated) in accordance with the improvement of depressive symptoms; there was a significant positive association between improvement on the Hamilton Depression Rating Scale (HDRS) score and improvement of executive function. During remission, overall executive function and the measures used to test, it were no longer different from the baseline performance of healthy controls. However, in a recent study with strictly defined inclusion criteria, only including patients that had been remitted for a substantial period of time, ${ }^{42)}$ multiple linear regression analyses with simultaneous adjustment for age, gender, education level, premorbid intelligence quotient (IQ), and residual depressive symptoms showed a diagnosis of MDD predicted lower performance on attention and processing speed (the Trail Making Test, the Symbol Digit Modalities Test) and on executive function (the Stroop test). The authors also reported that there was a trend toward the patient group performing worse than the healthy control group in all the tested cognitive domains including verbal/nonverbal memory, verbal function.

Recently, Bora et al. ${ }^{43)}$ conducted a systematic review and meta-analysis of cognitive deficits in studies of euthymic MDD patients compared with healthy controls. In global cognition, euthymic MDD patients showed significantly lower score compared with healthy controls $(d=0.47)$. Moreover, healthy controls significantly outperformed euthymic MDD patients in all cognitive domains. Task-specific analyses indicated that healthy controls performed significantly better than MDD patients in Stroop interference $(\mathrm{d}=0.74)$, Trail Making Test A $(\mathrm{d}=0.39)$, Trail Making Test $\mathrm{B}(\mathrm{d}=0.48)$, digit span backwards $(d=0.41)$, list learning $(d=0.42)$, list recall $(d=0.39)$, and animal naming $(\mathrm{d}=0.57)$, but not in phonetic fluency, Wisconsin Card Sorting Test perseveration, digit span forwards and list recognition.

Taken together, that majority of studies support the hypothesis that cognitive deficits exist in patients with MDD during periods of remission. Pooling of results in the previously described meta-analysis further supports this hypothesis. Measures of attention, executive function, and verbal memory were the most reproducibly reported cognitive domains affected, despite a few contradictory results. Although studies by Beats et al., ${ }^{44)}$ Clark et al., ${ }^{37)}$ and Biringer et al. ${ }^{29)}$ reported no significant difference in cognitive performance between remitted MDD patients and healthy controls, this discrepant findings may have resulted from the prevalent methodological drawbacks; studies used various diagnostic criteria (International Classification of Diseases-10; Diagnostic and Statistical Manual of Mental Disorders [DSM] third edition, revised; or DSM 4th edition), inconsistent cut-off values on depressive symptom scale score (cut-off scores were 6-8 on 
the HDRS and 5-12 on Montgomery-Åsberg Depression Rating Scale) and the strategies employed to assess whether participants were in a remitted state were diverse (some studies relied solely on a cut-off score, whereas the remaining studies included participants clinically remitted for a period of minimum of 1-6 months).

It also is noteworthy that although there has been strong evidence that some 'cold' cognitive abnormalities (as described above) do not disappear completely upon remission, some investigators emphasize the role of 'hot' cognition, particularly on tasks that utilize feedback, on which depressed patients have been reported to exhibit a "catastrophic response to perceived failure". ${ }^{45)}$ "Cold' cognition refers to information processing in the absence of any emotional influence. Theoretically, cold cognition is engaged on tests where the stimuli are emotionally neutral and the outcome of the test is not motivationally relevant; commonly used standardized neurocognitive test such as the California Verbal Learning Test, the TrailMaking Test, and the Wisconsin Card Sort Test are considered as 'cold' ${ }^{45)}$ 'Hot' cognition denotes emotion-laden cognitive processes, i.e., cognitive processes which are colored by feeling or emotion. ${ }^{45)}$ In MDD, 'hot' cognition is biased in attention, perception and memory for negative cues and/or perception and memory for positive cues are reduced ${ }^{46,47)}$ There has been considerable evidence that abnormalities in 'hot' cognition are observed in individuals with a history of depression and can be triggered by external stimuli although it appears to be resolved or absent in these patients following clinical remission. ${ }^{47,48)}$ For example, patients with remitted MDD also exhibit a persistent susceptibility to distraction by negative emotional information, which impedes their performance in 'cold' cognitive tasks. ${ }^{49)}$ In 1996, Beats et al ${ }^{44)}$ reported a pattern of behavior; when depressed patients made an error on a test, they were proportionately more likely than controls to make an error on the subsequent trial. The "catastrophic response to perceived failure" raises the possibility that at least some of the poor performance on neurocognitive tests in depression might be due to altered 'hot' cognition, which is trait related. ${ }^{50,51)}$ In summary, it is hypothesized that depression is associated with abnormalities in 'hot' cognition qualitatively (i.e., changes in the nature of the cognitive processes), as well as in 'cold' cognition quantitatively (i.e., neuropsychological performance deficits). These two aspects of cognition may exert mutual influences on each other. ${ }^{47)}$

\section{Cognitive Deficits Underlying Poor Occupational Functioning in Remitted MDD Patients}

As reviewed in the previous section, remitted MDD patients are impaired in their verbal/visual memory, visual-motor sequencing, attention, working memory and executive function. In several studies to explore the relationship between cognitive and functional outcome in MDD patients, performance in at least one cognitive domain (most commonly executive function, attention, psychomotor speed, and certain aspects of memory) was associated with functional outcome. ${ }^{52)}$ Moreover, there have been reports that cognitive impairment could be a contributing factor that determines levels of social and occupational impairment in different phases of MDD. ${ }^{53,54)}$ Here, we discuss the cognitive deficits underlying poor occupational functioning in remitted MDD patients.

\section{Relation between cognitive deficit and occupational disability in other conditions}

Although there have been studies for the effect of neurocognitive deficits as a mediator of occupational disability in schizophrenia and bipolar disorder, there has only been minimal investigation with MDD. Therefore, studies assessing cognition as a mediator of occupational disability in bipolar disorder and schizophrenia will be briefly reviewed. While these results may not be completely generalizable to the MDD population, they may provide some insight into occupational effects of impairment of the specific domains of cognition assessed.

In studies with schizophrenic patients, impaired attention was associated with poor occupational performance. Patient with difficulties in selective and sustained attention may be distracted easily by extraneous stimuli or internal thought causing difficulties in encoding relevant task information for processing and recall. ${ }^{55)}$ Poor sustained attention also means that they are unable to monitor engagement of a task for extended periods of time, resulting in concentration lapses that will delay completion of a work task. ${ }^{56-58)}$

Reduced ability in working memory and verbal learning may also impair work function. Problems in declarative working memory may induce the inability to retain and retrieve information during learning of new work tasks, therefore reducing acquisition of work skills. ${ }^{59,60)}$ Poor verbal learning is found to be associated with poorer work habits, poorer work quality and fewer number of hours worked in competitive jobs in patients with schizophrenia. ${ }^{61,62)}$ Impairment in executive function could also be a limiting factor in of occupational function for these 
patients. ${ }^{62)}$ The same study reported that improved executive functioning was associated with higher wages earned and more hours worked.

The neurocognitive factors including verbal learning and memory, and executive functioning were predictors of workplace performance in bipolar patients as well. Gilbert et $a l .{ }^{63)}$ found that self-reported cognitive impairment at baseline, especially concentration problem, increased the chances of not working at both baseline and follow-up of 15-43 months. A study using neurocognitive tests ${ }^{64)}$ reported that high scores on the measure of executive function, digits backwards test, was a predictor of lower occupational functioning. Verbal learning deficit assessed with the California Verbal Learning Test were independently associated with higher scores on the Strauss Carpenter work outcome scale, used to measure work disability. ${ }^{65)}$ The executive/reasoning scale independently predicted low versus high occupational adaptation in this study. Motor speed domain was predictive of occupational adaptation in schizophrenic patients. In bipolar patients, a composite neurocognitive score at baseline was the strongest independent predictor of good versus poor occupational adaptation and executive/reasoning domain predicted occupational adaptation level at one-year follow-up. In another study ${ }^{66)}$ with schizophrenic and bipolar I patients, a composite neurocognitive score at baseline was the strongest independent predictor of good versus poor occupational adaptation in schizophrenic and bipolar patients. Among the neurocognitive domains, independent predictors of occupational adaptation were the motor speed domain in schizophrenic patients and the executive/reasoning domain in bipolar patients. These cognitive abilities impaired in bipolar patients are related to learning new tasks, acting purposefully and making decisions. ${ }^{67)}$ Lee et al. ${ }^{68)}$ investigated cognitive markers that predict later socio-occupational functioning in outpatients with major psychiatric disorders among 93 young (mean 21.6 years old) patients $(\mathrm{MDD}=34$, bipolar $=34$, psychosis $=$ 29). At the point of follow-up after 21.6 months of baseline evaluation, the best independent predictors of good socio-occupational functioning were verbal and visual memory, working memory and executive functioning.

\section{Relation between cognitive deficit and occupational disability in symptomatic MDD}

There have been a few studies to support cognitive deficits in MDD specifically as a mediator of functional/occupational impairment. In a study aimed to characterize psychosocial and cognitive profiles among MDD and bipolar patients during a major depressive episode and to compare the profiles of the patient groups for 12 months, ${ }^{69)}$ psychosocial and neurocognitive functioning seem similar among MDD and bipolar patients during a depressive episode in the case of severe mood disorders. All MDD and bipolar patients had global psychosocial dysfunction, characterized by occupational and relational impairments. At the time point of follow-up, occupational and relational impairments, as well as neurocognitive dysfunction, persisted sufficiently to alter daily functioning of the patients. Naismith et $a l .^{70)}$ examined the relationship between subjective disability and subjective/objective measures of cognitive performance in MDD patients. A small sample $(n=21)$ of adults patients exhibited a moderate relationship between objectively measured psychomotor speed and self-rating cognitive deficits with physical disability. Functional disability was moderately correlated with objective measures of memory retention too. McIntyre et $a l^{71)}$ also evaluated the deleterious effect of cognitive deficits on functional outcomes in MDD including workplace performance. The authors noted that abnormalities in many cognitive domains of executive function, working memory, attention, and psychomotor processing speed may account for the largest percentage of variance with respect to the link between workforce performance and MDD.

\section{Relation between cognitive deficit and occupational disability in remitted MDD}

Baune et $a l .{ }^{72)}$ evaluated the association between cognitive dysfunction and MDD as compared with age- and gender-matched healthy controls in participants with current MDD $(n=26)$ and those with previous MDD only $(n=44)$. The mean HDRS-17 score in past MDD group was 6.8. The results showed that participants with previous MDD but who were currently employed performed significantly better in the visuospatial, language and delayed memory domains (except immediate memory and attention) as well as on the total score than their counterparts without employment. In another study which investigated the relationship between quality of life and neurocognitive dysfunction in patients with remitted MDD, ${ }^{73)}$ remitted MDD patients had poorer neurocognitive performances than healthy controls for psychomotor speed, attention, and verbal memory than age and education matched healthy subjects. Delayed verbal recall was associated with poor general health perceptions. Of note, the functional outcome was not evaluated in this study. In the results from Jaeger et al., ${ }^{22)}$ which examined the degree to 
which neurocognitive deficits explain functional outcome 6 months following hospitalization for a major depressive episode, five out of seven cognitive domains showed significant findings in models of concurrent associations at the 6-month time point. Most measures at 6 months follow-up within attention, ideational fluency, non-verbal (visuospatial) and learning domains were highly associated with life function disability at the 6-month time point, which means the degree to which neurocognitive deficits present at the 6-month time point are associated with level of functional recovery at that point. Cognitive impairment at acute phase of depression could predict poor occupational outcome after remission. Memory and executive function at admission was predictive of poor occupational function at approximately 4 months after discharge. ${ }^{74)}$ The significant cognitive predictors for Social and Occupational Function Assessment Scale at follow-up were shortened Wisconsin Card Sorting Test perseverative errors and prospective memory categories.

Taken together, cognitive deficits in memory, attention, learning and executive function appear to be mediators of impairment in vocational function. In addition, specific cognitive domains may exert more influence at certain phases of occupational adjustment after remission. Bryson and Bell ${ }^{61)}$ discovered that attention is more important for earlier phase of work performance, and verbal memory and psychomotor speed becomes more important for sustained improvement in work performance. It was postulated that learning new tasks with attention was more crucial in the initial phase of work, and cognitive demands shifted towards remembering instructions and keeping up with the speed of work at a later stage. ${ }^{61)}$ However, cognitive demands may be dependent on the type of jobs; a job requiring repetitive actions may have a higher demand on sustained attention, whereas a job requiring taking down orders will require verbal memory. ${ }^{58)}$ These suggestions from schizophrenia and bipolar disorder may potentially also be applied to remitted MDD patients. Further studies are still required to specifically assess the effects of cognitive dysfunction in MDD on workplace performance.

\section{Predictors of Neurocognitive Deficit Related to Occupational Function in Remitted MDD Patients}

There have been several demographic and clinical factors shown to be predictive of cognitive deficits in MDD. These factors include age, age at onset, duration of illness, episode frequency, baseline symptom severity, subtype of MDD, psychiatric/medical comorbidity and educational level (Table 2).
Age

Thomas et al. ${ }^{75)}$ compared neuropsychological performance of younger ( $<60$ years) and older ( $\geq 60$ years) adults with MDD and healthy controls. The late-life depression group had greater impairment in verbal learning, memory and motor speed but not in executive function. The authors suggested that late-life depression is associated with more severe impairment in verbal learning, memory and motor speed than depression in earlier adult life and this is not due to aging alone, while this study reported normal executive function in older patients. In a meta-regression analysis of studies in adults with a first-episode MDD, ${ }^{76)}$ age significantly contributed to heterogeneity in effect sizes in some cognitive domain. Studies with patients who were, on average, older than controls reported significantly worse performance for

Table 2. Predictors of cognitive deficits related to poor occupational function in remitted major depressive disorder patients

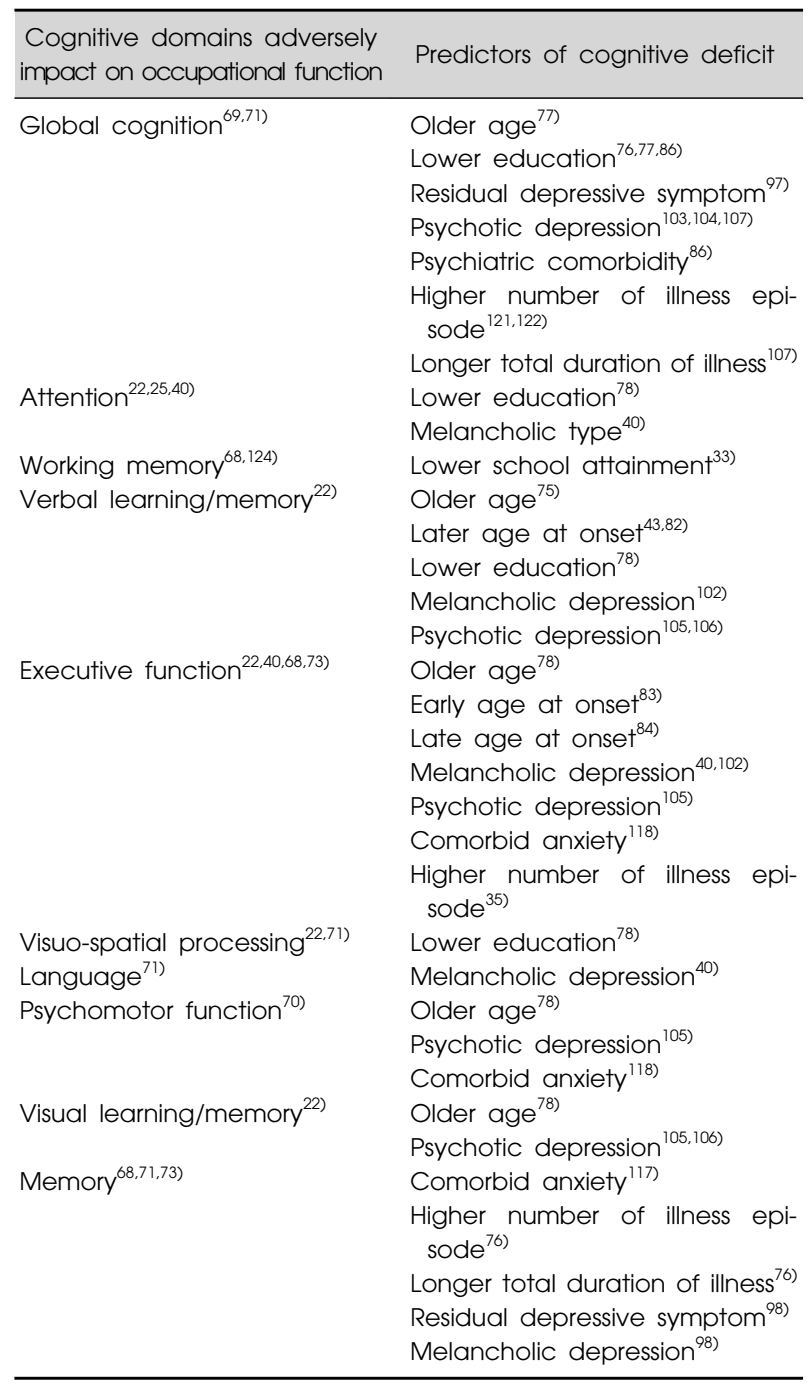


psychomotor speed, visual learning and memory, and all aspects of executive functioning examined.

In a recent study, age was positively associated with impaired executive functioning in euthymic MDD and bipolar I disorder patients. ${ }^{33)}$ Moreover, Gorwood et al. ${ }^{77)}$ reported higher age as independent predictor for poor memory function. These results support previous studies suggesting that higher age was associated with overall cognitive deficits in euthymic mood disorder patients. ${ }^{78)}$ However, In a recent meta-analysis with remitted MDD subjects of various clinical stage by Bora et al., ${ }^{43)}$ age had no statistically significant influence on the nature of cognitive deficits observed in euthymic MDD patients. Taken together, age appears to be an important factor for impairment in memory and learning function in MDD patients; however, results have been variable.

\section{Age at onset}

Herrmann et al. ${ }^{79)}$ compared early onset and late onset depression patients for white matter hyperintensities in manetic resonance imaging scans which have been known to be related to cognitive decline in various domains, particularly executive skills, attention and mental speed. ${ }^{80,81)}$ They reported that late onset depression was characterized by more frequent and intense white matter abnormalities. However, another study reported an association of impaired executive functioning with younger age at onset, ${ }^{82)}$ and no significant correlation between age at onset and cognitive performance. ${ }^{28)}$ In a relatively large study with remitted MDD patients, Wekking et al. ${ }^{83)}$ reported a correlation with later age of onset and a slower speed of information processing and lower verbal memory performance. Moreover, in a recent meta-analysis with remitted MDD subjects by Bora et al., ${ }^{43)}$ cognitive deficits in late onset patients (onset after 50-65 years, depending on the study) were significantly more severe than those in early onset patients in terms of processing speed and verbal memory. There were also trend level differences for global cognition and executive function. In meta-regression analyses, older age of onset was associated with more severe verbal memory deficits.

However, in another recent study by Daniel et al., ${ }^{33)}$ age at onset was not correlated with executive functioning, working memory or verbal memory in euthymic MDD or bipolar I disorder patients. But the authors noted that the association between performance on neurocognitive tasks and age at onset could be overshadowed by associations between performance on neurocognitive tasks and education.

Age at onset could therefore be a mediating factor of cognitive impairment in MDD. Patients with early onset may suffer predominantly from impaired episodic memory, and those with late-onset mainly from reductions of executive function and processing speed. ${ }^{84)}$ Presence of structural abnormalities such as vascular lesions in late onset subjects may account for the severe cognitive defecits seen in late onset depression. ${ }^{79,85)}$ Although this is a subject of ongoing discussion, age of onset may be associated with different risk factors including genetic predisposition to developing recurrent depression, somatic disease and vascular pathology. ${ }^{24)}$

\section{Education}

Educational attainment in patients may be predicted to correlate with higher neuropsychological performance. ${ }^{33)}$ In a recent meta-regression analysis of studies in adults with a first-episode MDD, ${ }^{76)}$ patients with lower levels of education showed more severe deficits in cognitive functioning in first-episode MDD. In this study, patient groups that were, on average, less educated than controls demonstrated worse verbal learning and memory, visual learning and memory, and attentional switching; yet, higher levels of education in patients relative to controls appeared to mitigate learning and memory and attentional switching deficits in first-episode MDD. In euthymic state, Gildengers et $a l .{ }^{78)}$ reported that patients with MDD and bipolar disorder were impaired across all cognitive domains compared with controls. The impairment was most prominently in information processing speed and executive function. In this study, worse overall cognitive function was associated with lower education. ${ }^{78)}$ This is in line with the results from a previous study; Gorwood et al. ${ }^{77)}$ reported education level as an independent factor for overall cognitive performance, and education level was significantly related to immediate memory, language, delayed memory, and the total score, ${ }^{86)}$ even though these studies did not restrict inclusion to remitted patients. Considering overall results, education seems to provide some protection against deficits on cognitive function, especially on executive function and memory in patients with MDD as noted by Kurtz and Gerraty. ${ }^{87)}$

\section{Severity of depressive symptom}

Increased severity of depression may be related to greater impairment on cognitive performance and the relationship between symptom severity and cognitive impairment could differ across cognitive domains. Several authors have suggested that increased severity of depression was related to greater impairment on overall cognitive 
function, ${ }^{88)}$ executive function, ${ }^{89,90)}$ processing speed, ${ }^{89)}$ and semantic memory. ${ }^{90)}$ However, there have been contradictory findings on overall cognition, ${ }^{91)}$ executive function, ${ }^{92,93)}$ episodic memory, ${ }^{94)}$ semantic memory, ${ }^{89,90)}$ visuo-spatial memory, ${ }^{95)}$ and processing speed ${ }^{88,89)}$ In 2009 , McDermott and Ebmeier ${ }^{96)}$ conducted a meta-analysis to examine the relationship between severity of depression and cognitive function. The results showed significant correlations between depression severity and cognitive performance in some domains of cognitive function (e.g., episodic memory, executive function, and processing speed), yet there were limitations to this analysis, namely, a small number of included studies and heterogeneity in methodological designs and outcome measures.

Since the majority of previous studies which investigated relationship between depressive symptom severity and cognitive functions have concentrated on the acute phase of illness and were not specifically concerned with euthymic patients, the evidence of cognitive dysfunctions in remitted depression remain insufficient and unclear. Some authors have suggested that the patients with higher residual symptom severity more likely to have significant neurocognitive deficits. ${ }^{97)}$ Weiland-Fiedler et $a l .{ }^{34)}$ compared cognitive performance in remitted MDD patients with controls. They suggested that residual depressive symptoms influence cognitive function in remitted MDD patients because deficits in some cognitive domain lost statistical significance after correction for residual depressive symptoms. In a study comparing 20 inpatients recently remitted from severe MDD with 20 healthy matched control participants on learning tasks, high scores on Beck's Depression Inventory was correlated with poorer explicit learning. ${ }^{98)}$

However, relatively recent studies did not agree with this association in remitted MDD patients. Preiss et al. ${ }^{30)}$ reported that the individual level of depressive symptoms was not related to the cognitive performance in euthymic MDD patients. Wekking et al ${ }^{83)}$ performed standardized neuropsychological tests of mental speed, memory and executive functioning in 137 recurrent, remitted patients as part of a larger randomized controlled clinical trial and compared with clinically used published normative data. There was non-significant correlation between neuropsychological test scores and residual depressive symptoms. A meta-analysis published recently ${ }^{43)}$ supported these results by showing that current (i.e., residual) depressive symptoms had no statistically significant influence on the nature of cognitive deficits observed in euthymic MDD patients. Taken together, there appears to be no clear asso- ciation between cognitive function and residual symptom severity; however, there is still debate in this area and further studies are needed.

\section{Subtype of depressive episode}

The inconsistent findings from researches concerning cognition in depression could be caused by the effects of heterogeneity between patients with mixed melancholic and non-melancholic subtype of MDD. Several works have reported qualitative cognitive changes associated with acute melancholic depression across a number of domains, namely, psychomotor speed, ${ }^{99)}$ memory functions of learning ${ }^{100)}$ and delayed recall, ${ }^{101)}$ and executive functions. $88,100,101)$

In a longitudinal study comparing the cognitive performance of patients with melancholic and non-melancholic $\mathrm{MDD}^{102)}$ at acute admission and 3 months after recovery, melancholic patients performed more poorly on tests requiring memory acquisition, mental flexibility, set-shifting, selective attention, concept-formation and multi-tasking compared to those with non-melancholic depression after correcting for depression severity. The authors reported no group-by time differences for any of the memory or executive function measures showing that these groups had a comparable rate of improvement in task performance over time. These results suggested that the melancholic group was more impaired at follow-up but this was consistent with the group initially presenting with more severe cognitive dysfunction. Pedersen et al. ${ }^{98)}$ studied patients who recently remitted from severe MDD and reported that although not statistically significant, patients remitted from melancholic MDD revealed poorer implicit learning performance compared with patients remitted from non-melancholic MDD.

Psychotic features during the course of MDD could also be predictive of poorer cognitive performance. In a meta-analytic study on psychotic depression, the authors reported that patients with psychotic symptoms are more cognitively impaired than non-psychotic depressed subjects. ${ }^{103)}$ Bora et al ${ }^{104)}$ have reported that patients with affective psychoses in general are significantly impaired in many cognitive tasks, with large effect sizes for most measures. The domains of cognitive function affected by the presence of psychotic depression include executive function, verbal and visual memory, and psychomotor skills. ${ }^{105)}$ In a recent meta-analysis which compared neurocognitive performance between non-psychotic MDD versus psychotic MDD, psychotic MDD was impaired in verbal learning/memory, visual learning/memory, and 
processing speed. ${ }^{106)}$ Hasselbalch et al. ${ }^{107)}$ showed significant associations between global cognition and the cumulative duration/total number of psychotic depression and they implied that a history of psychotic depression may be the strongest predictor of future impairment in most domains of cognitive function.

\section{Comorbidity}

Large numbers of patients suffer from MDD comorbid with medical illness, such cardiovascular disease, stroke, diabetes and cancer ${ }^{108)}$ which can also independently negatively impact cognitive function. ${ }^{109)}$ For example, diabetes $^{110-112)}$ and vascular illness ${ }^{13,114)}$ have been associated with independent adverse effects on cognitive function. Moreover, psychiatric comorbidities such as substance abuse and anxiety are important to consider in depressed patients because of their independent potential effects on cognition. Lots of studies reported association of cognitive impairment with substance use disorders and anxiety disorders. ${ }^{115)}$ Kizilbash et al. ${ }^{116)}$ reported that there was an adverse effect on memory (specifically, immediate recall and amount of acquisition, and the retrieval of newly learned information) when depression was compounded by anxiety. This result was replicated in elderly MDD subjects who had responded to treatment; DeLuca et al. ${ }^{117)}$ followed up to four years at yearly intervals with assessment of their symptoms, cognitive status, and functional disability. The anxious group showed a greater decline in memory than non-anxious, but not in other cognitive measures or measures of functional status. Comorbid anxiety disorder may impair executive function and psychomotor speed. Basso et al. ${ }^{118)}$ compared nonpsychotic depressed inpatients with and without comorbid anxiety disorders. Both groups of depressed patients showed worse memory function than normal control group. The comorbid anxiety group had more impaired in executive function and psychomotor function than non-anxious depressed group.

For general psychiatric comorbidities, Baune et al. ${ }^{86)}$ investigated the association between cognitive performance and psychiatric and medical comorbidity in depression. They evaluated the cognitive performance of patients diagnosed as bipolar disorder with a major depressive episode or MDD in relation to the presence of medical and/or psychiatric comorbidity. The subjects divided into four groups of comorbidity; no comorbidity, medical comorbidity, psychiatric comorbidity, and both medical and psychiatric comorbidity. The result showed that psychiatric comorbidity significantly decreased cognitive per- formance in the visuospatial/constructional and the language domains and the total score. In addition, increasing numbers of psychiatric comorbidities were related to worse cognitive performance. In contrast, medical comorbidity alone had no impact on any of the domains of cognitive performance. There was an additive effect of medical and psychiatric comorbidities in depression on visuospatial/ constructional cognitive abilities. The authors suggested that the strongest predictor of poor cognitive performance in depression was psychiatric comorbidity.

\section{Number of episodes / Duration of illness}

It has been found from brain imaging studies that repeated and prolonged duration of depressive episodes is associated with structural changes in brain regions which mediate some of the cognitive aspects of depression. ${ }^{119,120)}$ Number of mood episodes and lifetime duration of illness seem to contribute to cognitive impairment in asymptomatic states, ${ }^{121,122)}$ and number of episodes may be more closely linked to the degree of global cognitive impairment than the total duration of illness. ${ }^{121)}$ However, prior studies are sparse and report divergent results.

Kessing ${ }^{121}$ found cognitive impairment to be associated with the number of mood episodes experienced, but the duration of the illness had no significant effect on cognitive function. In another study, it was found that patients who suffered more than two episodes were more impaired than patients with one or two episodes on executive function. ${ }^{35)}$ Bhardwaj et al. ${ }^{123)}$ proposed two possible explanations for these results. The first one is that cognitive impairments could be a trait marker for more recurrent depression rather than being a consequence of the depressive state. The second explanation is the concept of 'kindling', in which the early multiple episodes cause permanent change to the neural substrates of neurocognitive performance that makes subsequent episodes more likely. Moreover, such a residue might also explain the existence of cognitive deficits in remission.

In a study with a large sample $(n=8,229)$ of MDD outpatients, ${ }^{77)}$ among those 1,895 patients whose Hospital Anxiety and Depression Scale depression score decreased by $50 \%$ at the second visit (on average 42 days later), the number of past episodes and total length of MDD constituted a cluster that was significantly correlated with memory performance. The authors suggested there could be a toxic link between the burden of depression and cognition. Recently, Hasselbalch et al. ${ }^{107)}$ investigated the relationship of cognition and duration of illness with the Danish registry, and the results showed an association be- 
tween the cumulative duration of depressive episodes and a decreased cognitive performance adjusted for age, gender, education, premorbid IQ and residual depressive symptoms.

On the contrary, no association between number of episodes and cognitive impairment was found in several studies. ${ }^{28,30,44)}$ Reischies and $\mathrm{Neu}^{26)}$ also reported that no correlation between the duration of the disease or number of episodes and cognitive deficits could be found. Lifetime duration of illness was not related to any cognitive domain or global cognition among bipolar and MDD subjects in another study. ${ }^{78)}$ Non-significant correlation of neuropsychological test scores with number of pervious episodes was supported by a relatively large study $(\mathrm{n}=137)$ by Wekking et al. ${ }^{83)}$ In a recent study by Daniel et al., ${ }^{33)}$ there was no correlation with number of episodes and deficits in cognitive performance including executive functioning, working memory or verbal memory in euthymic MDD or bipolar I disorder patients. However, the authors noted that the association between performance on neurocognitive tasks and number of episodes of illness might be overshadowed by associations between performance on neurocognitive tasks and education. Furthermore, in a recent meta-regression analyses, the number of episodes and duration of illness had no statistically significant influence on the nature of cognitive deficits observed in euthymic MDD patients. ${ }^{43}$ In summary, the data indicate that subjects and measurements are not consistent and homogeneous enough to reliably detect subtle effects of illness duration/number of episodes on cognitive performance.

\section{Interventions on Occupational Function in Remitted Depression Patients}

For depressed workers, a few modalities of intervention that can improve occupational functioning have been suggested and some of those are considered as effective. In a recent Cochrane review, ${ }^{124)}$ work-directed intervention, ${ }^{125-127}$ and cognitive behavioural therapy that was provided online or by telephone ${ }^{128-130)}$ were effective in improving occupational function. Although small and inconclusive, a small number of studies which examined cognitive remediation in MDD suggested that cognitive remediation could be an effective approach. ${ }^{131-135)}$ For pharmacotherapy, in studies compared effectiveness on improving occupational function between selective serotonin reuptake inhibitor (SSRI) to serotonin-norepinephrine reuptake inhibitor (SNRI), the result from one study ${ }^{136)}$ favored SSRI. On the other hand, there was no difference in sickness absence in two studies, ${ }^{137,138)}$ and the meta-analysis. ${ }^{124)}$
However, the above reports did not address occupational function in remitted depression patients although recent studies have indicated that residual cognitive deficits including attention, executive function, and verbal memory are repeatedly reported in remitted MDD patients. Because we were unable to find any studies which evaluated the effectiveness of interventions on occupational function in remitted subjects, it is hard to say whether the interventions effectively improving occupational functioning in depressed subjects is also effective in remitted depression patients or not. In that residual cognitive deficits appear to be mediators of occupational impairment in remitted state of MDD, interventions ameliorate cognitive deficit could improve occupational function as well. In 2010, Naismith et al. ${ }^{139)}$ studied sixteen patients with a lifetime diagnosis of MDD but who had not clinical depressive symptom at recruitment. The subjects were randomly allocated to treatment or waitlist control conditions. The treatment consisted of 1 hour twice a week for 10 weeks cognitive training using the Neuropsychological Educational Approach to Remediation (NEAR). After 10 weeks, participants in the treatment condition demonstrated greater improvements on tests of memory encoding and memory retention than the control group. Naismith et $a l .{ }^{140)}$ also studied the effect of NEAR in geriatric depression patients. The subjects had a lifetime history of MDD but were 'stabilized on medication' and had depressive symptoms in the normal to mild range. The treatment consisted of weekly 1-hour sessions of computerized cognitive training. In addition, there was a weekly 1-hour group session of psychoeducation. Once again, cognitive training was associated with positive and significant effects on learning and memory. As the authors suggested, cognitive training may be an effective non-pharmacological treatment option for improving cognitive functions, which in turn, may improve psychosocial functioning and reduce disability. ${ }^{139)}$

\section{CONCLUSION}

Converging evidence is accumulating for cognitive impairment in various cognitive domains in remitted MDD. Recent studies have indicated that attention, executive function, and verbal memory are the most repeatedly reported cognitive domains as impaired in remitted MDD patients. These residual cognitive deficits in remitted patients appear to be mediators of impairment in occupational function in remitted state of MDD. However, due to the heterogeneity in the design of the included studies, 
definitions of remission, clinical characteristics of the included samples, and lack of well-designed studies, suggesting definitive determinants for impairment in cognitive and occupational performance is difficult to assert at this time. Certain features may be predictive of vocational adjustment difficulties prospectively in remitted MDD patients; higher age, late age at onset, residual depressive symptom, history of melancholic/psychotic depression, and physical/psychiatric comorbidity may negatively affect cognitive function related to occupational accommodation and higher levels of education may have protective effect against cognitive deficit.

To date, there are very few published studies that have examined the relationship between cognitive function and social/occupational difficulty in remitted MDD patients, and these studies have some significant methodological limitations. Further studies include larger and more homogeneous samples, with more extensive and validated assessments of psychosocial and occupational function and multivariate statistical methods, are clearly necessary and warranted.

\section{- Acknowledgments}

Young Sup Woo, Won-Myong Bahk, Joshua D. Rosenblat, and Ron Kakar have no conflicts of interest. Roger S. McIntyre has received research grant support from Lundbeck, Astra Zeneca, Pfizer, Shire, Otsuka, Bristol Myers Squibb, National Institute of Mental Health, Stanley Medical Research Institute, Canadian Institutes for Health Research, and The Brain and Behavior Research Foundation. Dr. McIntyre has also received speaker/consultant fees from Lundbeck, Pfizer, Astra Zeneca, Elli Lilly, Janssen Ortho, Sunovion, Takeda, Forest, Otsuka, Bristol Myers Squibb and Shire.

\section{REFERENCES}

1. Hamet P, Tremblay J. Genetics and genomics of depression. Metabolism 2005;54(5 Suppl 1):10-15.

2. Kessler RC, Berglund P, Demler O, Jin R, Koretz D, Merikangas KR, et al; National Comorbidity Survey Replication. The epidemiology of major depressive disorder: results from the National Comorbidity Survey Replication (NCS-R). JAMA 2003;289:3095-3105.

3. Bakish D. New standard of depression treatment: remission and full recovery. J Clin Psychiatry 2001;62 Suppl 26: $5-9$.

4. Hirschfeld RM, Dunner DL, Keitner G, Klein DN, Koran LM, Kornstein SG, et al. Does psychosocial functioning improve independent of depressive symptoms? A comparison of nefazodone, psychotherapy, and their combination. Biol Psychiatry 2002;51:123-133.

5. Miller IW, Keitner GI, Schatzberg AF, Klein DN, Thase ME, Rush AJ, et al. The treatment of chronic depression, part 3: psychosocial functioning before and after treatment with sertraline or imipramine. J Clin Psychiatry 1998;59: 608-619.

6. Moussavi S, Chatterji S, Verdes E, Tandon A, Patel V, Ustun B. Depression, chronic diseases, and decrements in health: results from the World Health Surveys. Lancet 2007;370:851-858.

7. Murray CJ, Lopez AD. Evidence-based health policy-lessons from the Global Burden of Disease Study. Science 1996;274:740-743.

8. Murray CJL, Lopez AD, Harvard School of Public Health, World Health Organization, World Bank. The global burden of disease: a comprehensive assessment of mortality and disability from diseases, injuries, and risk factors in 1990 and projected to 2020. Cambridge, MA:Published by Harvard School of Public Health on behalf of the World Health Organization and the World Bank; Distributed by Harvard University Press; 1996.

9. Judd LL, Akiskal HS, Zeller PJ, Paulus M, Leon AC, Maser JD, et al. Psychosocial disability during the longterm course of unipolar major depressive disorder. Arch Gen Psychiatry 2000;57:375-380.

10. Gotlib IH, Lewinsohn PM, Seeley JR. Symptoms versus a diagnosis of depression: differences in psychosocial functioning. J Consult Clin Psychol 1995;63:90-100.

11. Judd LL, Akiskal HS, Paulus MP. The role and clinical significance of subsyndromal depressive symptoms (SSD) in unipolar major depressive disorder. J Affect Disord 1997;45:5-17; discussion 17-18.

12. Judd LL, Rapaport MH, Paulus MP, Brown JL. Subsyndromal symptomatic depression: a new mood disorder? J Clin Psychiatry 1994;55 Suppl:18-28.

13. Lam RW, Filteau MJ, Milev R. Clinical effectiveness: the importance of psychosocial functioning outcomes. J Affect Disord 2011;132 Suppl 1:S9-S13.

14. Greer TL, Kurian BT, Trivedi MH. Defining and measuring functional recovery from depression. CNS Drugs 2010;24:267-284.

15. Judd LL, Schettler PJ, Solomon DA, Maser JD, Coryell W, Endicott $\mathrm{J}$, et al. Psychosocial disability and work role function compared across the long-term course of bipolar I, bipolar II and unipolar major depressive disorders. $J$ Affect Disord 2008;108:49-58.

16. Kessler RC, Akiskal HS, Ames M, Birnbaum H, Greenberg P, Hirschfeld RM, et al. Prevalence and effects of mood disorders on work performance in a nationally representative sample of U.S. workers. Am J Psychiatry 2006;163: 1561-1568.

17. Veiel HO. A preliminary profile of neuropsychological deficits associated with major depression. J Clin Exp Neuropsychol 1997; 19:587-603.

18. Elliott R. Executive functions and their disorders. Br Med Bull 2003;65:49-59.

19. Burt DB, Zembar MJ, Niederehe G. Depression and memory impairment: a meta-analysis of the association, its pattern, and specificity. Psychol Bull 1995;117:285-305.

20. Ravnkilde B, Videbech P, Clemmensen K, Egander A, Rasmussen NA, Rosenberg R. Cognitive deficits in major depression. Scand J Psychol 2002;43:239-251.

21. Conradi HJ, Ormel J, de Jonge P. Presence of individual (residual) symptoms during depressive episodes and periods of remission: a 3-year prospective study. Psychol Med 2011;41:1165-1174.

22. Jaeger J, Berns S, Uzelac S, Davis-Conway S. Neurocognitive deficits and disability in major depressive disorder. Psychiatry 
Res 2006; 145:39-48.

23. Snyder HR. Major depressive disorder is associated with broad impairments on neuropsychological measures of executive function: a meta-analysis and review. Psychol Bull 2013;139:81-132.

24. Hasselbalch BJ, Knorr U, Kessing LV. Cognitive impairment in the remitted state of unipolar depressive disorder: a systematic review. J Affect Disord 2011;134:20-31.

25. Buist-Bouwman MA, Ormel J, de Graaf R, de Jonge P, van Sonderen E, Alonso J, et al; ESEMeD/MHEDEA 2000 investigators. Mediators of the association between depression and role functioning. Acta Psychiatr Scand 2008;118: 451-458.

26. Reischies FM, Neu P. Comorbidity of mild cognitive disorder and depression--a neuropsychological analysis. Eur Arch Psychiatry Clin Neurosci 2000;250:186-193.

27. Paradiso S, Lamberty GJ, Garvey MJ, Robinson RG. Cognitive impairment in the euthymic phase of chronic unipolar depression. J Nerv Ment Dis 1997;185:748-754.

28. Neu P, Bajbouj M, Schilling A, Godemann F, Berman RM, Schlattmann P. Cognitive function over the treatment course of depression in middle-aged patients: correlation with brain MRI signal hyperintensities. J Psychiatr Res 2005; 39:129-135.

29. Biringer E, Mykletun A, Sundet K, Kroken R, Stordal KI, Lund A. A longitudinal analysis of neurocognitive function in unipolar depression. J Clin Exp Neuropsychol 2007;29: 879-891.

30. Preiss M, Kucerova H, Lukavsky J, Stepankova H, Sos P, Kawaciukova R. Cognitive deficits in the euthymic phase of unipolar depression. Psychiatry Res 2009;169:235-239.

31. Clark L, Sarna A, Goodwin GM. Impairment of executive function but not memory in first-degree relatives of patients with bipolar I disorder and in euthymic patients with unipolar depression. Am J Psychiatry 2005;162:1980-1982.

32. Smith DJ, Muir WJ, Blackwood DH. Neurocognitive impairment in euthymic young adults with bipolar spectrum disorder and recurrent major depressive disorder. Bipolar Disord 2006;8:40-46.

33. Daniel BD, Montali A, Gerra ML, Innamorati M, Girardi $\mathrm{P}$, Pompili M, et al. Cognitive impairment and its associations with the path of illness in affective disorders: a comparison between patients with bipolar and unipolar depression in remission. J Psychiatr Pract 2013;19:275-287.

34. Weiland-Fiedler P, Erickson K, Waldeck T, Luckenbaugh DA, Pike D, Bonne O, et al. Evidence for continuing neuropsychological impairments in depression. $J$ Affect Disord 2004;82:253-258.

35. Paelecke-Habermann Y, Pohl J, Leplow B. Attention and executive functions in remitted major depression patients. $J$ Affect Disord 2005;89:125-135.

36. Kaneda Y. Verbal working memory impairment in patients with current episode of unipolar major depressive disorder and in remission. Clin Neuropharmacol 2009;32:346-347.

37. Clark L, Kempton MJ, Scarnà A, Grasby PM, Goodwin GM. Sustained attention-deficit confirmed in euthymic bipolar disorder but not in first-degree relatives of bipolar patients or euthymic unipolar depression. Biol Psychiatry 2005;57. 183-187.

38. Nakano Y, Baba H, Maeshima H, Kitajima A, Sakai Y, Baba $\mathrm{K}$, et al. Executive dysfunction in medicated, remitted state of major depression. J Affect Disord 2008;111:46-51.

39. Yuan Y, Zhang Z, Bai F, Yu H, Shi Y, Qian Y, et al. Abnormal neural activity in the patients with remitted geriatric depression: a resting-state functional magnetic resonance imaging study. J Affect Disord 2008;111:145-152.

40. Lin K, Xu G, Lu W, Ouyang H, Dang Y, Lorenzo-Seva $\mathrm{U}$, et al. Neuropsychological performance in melancholic, atypical and undifferentiated major depression during depressed and remitted states: a prospective longitudinal study. J Affect Disord 2014;168:184-191.

41. Biringer E, Lundervold A, Stordal K, Mykletun A, Egeland $\mathrm{J}$, Bottlender R, et al. Executive function improvement upon remission of recurrent unipolar depression. Eur Arch Psychiatry Clin Neurosci 2005;255:373-380.

42. Hasselbalch BJ, Knorr U, Hasselbalch SG, Gade A, Kessing LV. Cognitive deficits in the remitted state of unipolar depressive disorder. Neuropsychology 2012;26: 642-651.

43. Bora E, Harrison BJ, Yücel M, Pantelis C. Cognitive impairment in euthymic major depressive disorder: a metaanalysis. Psychol Med 2013;43:2017-2026.

44. Beats BC, Sahakian BJ, Levy R. Cognitive performance in tests sensitive to frontal lobe dysfunction in the elderly depressed. Psychol Med 1996;26:591-603.

45. Roiser JP, Sahakian BJ. Hot and cold cognition in depression. CNS Spectr 2013;18:139-149.

46. Harmer CJ, Goodwin GM, Cowen PJ. Why do antidepressants take so long to work? A cognitive neuropsychological model of antidepressant drug action. Br J Psychiatry 2009; 195:102-108.

47. Miskowiak KW, Carvalho AF. 'Hot' cognition in major depressive disorder: a systematic review. CNS Neurol Disord Drug Targets 2014;13:1787-1803.

48. Leppänen JM. Emotional information processing in mood disorders: a review of behavioral and neuroimaging findings. Curr Opin Psychiatry 2006;19:34-39.

49. Kerestes R, Ladouceur CD, Meda S, Nathan PJ, Blumberg HP, Maloney K, et al. Abnormal prefrontal activity subserving attentional control of emotion in remitted depressed patients during a working memory task with emotional distracters. Psychol Med 2012;42:29-40.

50. Foland-Ross LC, Cooney RE, Joormann J, Henry ML, Gotlib IH. Recalling happy memories in remitted depression: a neuroimaging investigation of the repair of sad mood. Cogn Affect Behav Neurosci 2014;14:818-826.

51. Mackinger HF, Pachinger MM, Leibetseder MM, Fartacek RR. Autobiographical memories in women remitted from major depression. J Abnorm Psychol 2000;109:331-334.

52. Evans VC, Iverson GL, Yatham LN, Lam RW. The relationship between neurocognitive and psychosocial functioning in major depressive disorder: a systematic review. $J$ Clin Psychiatry 2014;75:1359-1370.

53. Fennig S, Mottes A, Ricter-Levin G, Treves I, Levkovitz Y. Everyday memory and laboratory memory tests: general function predictors in schizophrenia and remitted depression. J Nerv Ment Dis 2002;190:677-682.

54. Yen YC, Rebok GW, Gallo JJ, Jones RN, Tennstedt SL. Depressive symptoms impair everyday problem-solving ability through cognitive abilities in late life. Am J Geriatr Psychiatry 2011;19:142-150.

55. Sohlberg MM, Mateer CA. Cognitive rehabilitation: an integrative neuropsychological approach. New York:Guilford Press; 2001.

56. McGurk SR, Meltzer HY. The role of cognition in vocational functioning in schizophrenia. Schizophr Res 2000; 45:175-184.

57. McGurk SR, Mueser KT. Cognitive functioning, symptoms, and work in supported employment: a review and heuristic model. Schizophr Res 2004;70:147-173. 
58. Tan BL. Profile of cognitive problems in schizophrenia and implications for vocational functioning. Aust Occup Ther J 2009;56:220-228.

59. Liberman RP, Wallace CJ, Hassell J. Rehab rounds: Predicting readiness and responsiveness to skills training: the Micro-Module Learning Test. Psychiatr Serv 2004;55:764766.

60. Sergi MJ, Kern RS, Mintz J, Green MF. Learning potential and the prediction of work skill acquisition in schizophrenia. Schizophr Bull 2005;31:67-72.

61. Bryson G, Bell MD. Initial and final work performance in schizophrenia: cognitive and symptom predictors. J Nerv Ment Dis 2003;191:87-92.

62. McGurk SR, Mueser KT, Harvey PD, LaPuglia R, Marder J. Cognitive and symptom predictors of work outcomes for clients with schizophrenia in supported employment. Psychiatr Serv 2003;54:1129-1135.

63. Gilbert AM, Olino TM, Houck P, Fagiolini A, Kupfer DJ, Frank E. Self-reported cognitive problems predict employment trajectory in patients with bipolar I disorder. J Affect Disord 2010;124:324-328.

64. Bonnín CM, Martínez-Arán A, Torrent C, Pacchiarotti I, Rosa $\mathrm{AR}$, Franco $\mathrm{C}$, et al. Clinical and neurocognitive predictors of functional outcome in bipolar euthymic patients. a long-term, follow-up study. J Affect Disord 2010;121: 156-160.

65. Burdick KE, Goldberg JF, Harrow M. Neurocognitive dysfunction and psychosocial outcome in patients with bipolar I disorder at 15-year follow-up. Acta Psychiatr Scand 2010;122:499-506.

66. Tabarés-Seisdedos R, Balanzá-Martínez V, Sánchez-Moreno $\mathrm{J}$, Martinez-Aran A, Salazar-Fraile J, Selva-Vera G, et al. Neurocognitive and clinical predictors of functional outcome in patients with schizophrenia and bipolar I disorder at one-year follow-up. J Affect Disord 2008;109:286-299.

67. Gilbert E, Marwaha S. Predictors of employment in bipolar disorder: a systematic review. J Affect Disord 2013;145: 156-164.

68. Lee RS, Hermens DF, Redoblado-Hodge MA, Naismith SL, Porter MA, Kaur M, et al. Neuropsychological and socio-occupational functioning in young psychiatric outpatients: a longitudinal investigation. PLoS One 2013;8:e58176.

69. Godard J, Baruch P, Grondin S, Lafleur MF. Psychosocial and neurocognitive functioning in unipolar and bipolar depression: a 12-month prospective study. Psychiatry Res 2012;196:145-153.

70. Naismith SL, Longley WA, Scott EM, Hickie IB. Disability in major depression related to self-rated and objectively-measured cognitive deficits: a preliminary study. BMC Psychiatry 2007;7:32.

71. McIntyre RS, Cha DS, Soczynska JK, Woldeyohannes HO, Gallaugher LA, Kudlow $\mathrm{P}$, et al. Cognitive deficits and functional outcomes in major depressive disorder: determinants, substrates, and treatment interventions. Depress Anxiety 2013;30:515-527.

72. Baune BT, Miller R, McAfoose J, Johnson M, Quirk F, Mitchell $\mathrm{D}$. The role of cognitive impairment in general functioning in major depression. Psychiatry Res 2010;176: 183-189.

73. Shimizu Y, Kitagawa N, Mitsui N, Fujii Y, Toyomaki A, Hashimoto $\mathrm{N}$, et al. Neurocognitive impairments and quality of life in unemployed patients with remitted major depressive disorder. Psychiatry Res 2013;210:913-918.

74. Withall A, Harris LM, Cumming SR. The relationship between cognitive function and clinical and functional out- comes in major depressive disorder. Psychol Med 2009;39: 393-402.

75. Thomas AJ, Gallagher P, Robinson LJ, Porter RJ, Young $\mathrm{AH}$, Ferrier IN, et al. A comparison of neurocognitive impairment in younger and older adults with major depression. Psychol Med 2009;39:725-733.

76. Lee RS, Hermens DF, Porter MA, Redoblado-Hodge MA. A meta-analysis of cognitive deficits in first-episode Major Depressive Disorder. J Affect Disord 2012;140:113-124.

77. Gorwood P, Corruble E, Falissard B, Goodwin GM. Toxic effects of depression on brain function: impairment of delayed recall and the cumulative length of depressive disorder in a large sample of depressed outpatients. Am J Psychiatry 2008;165:731-739.

78. Gildengers AG, Butters MA, Chisholm D, Anderson SJ, Begley A, Holm M, et al. Cognition in older adults with bipolar disorder versus major depressive disorder. Bipolar Disord 2012;14:198-205.

79. Herrmann LL, Le Masurier M, Ebmeier KP. White matter hyperintensities in late life depression: a systematic review. J Neurol Neurosurg Psychiatry 2008;79:619-624.

80. Kramer-Ginsberg E, Greenwald BS, Krishnan KR, Christiansen B, Hu J, Ashtari M, et al. Neuropsychological functioning and MRI signal hyperintensities in geriatric depression. Am J Psychiatry 1999; 156:438-444.

81. Murata T, Kimura H, Omori M, Kado H, Kosaka H, lidaka $\mathrm{T}$, et al. MRI white matter hyperintensities, (1)H-MR spectroscopy and cognitive function in geriatric depression: a comparison of early-and late-onset cases. Int $J$ Geriatr Psychiatry 2001;16:1129-1135.

82. Castaneda AE, Suvisaari J, Marttunen M, Perälä J, Saarni SI, Aalto-Setälä T, et al. Cognitive functioning in a population-based sample of young adults with anxiety disorders. Eur Psychiatry 2011;26:346-353.

83. Wekking EM, Bockting CL, Koeter MW, Schene AH. Cognitive functioning in euthymic recurrently depressed patients: relationship with future relapses and prior course of disease. J Affect Disord 2012;141:300-307.

84. Herrmann LL, Goodwin GM, Ebmeier KP. The cognitive neuropsychology of depression in the elderly. Psychol Med 2007;37:1693-1702.

85. Salloway S, Malloy P, Kohn R, Gillard E, Duffy J, Rogg $\mathrm{J}$, et al. MRI and neuropsychological differences in earlyand late-life-onset geriatric depression. Neurology 1996; 46:1567-1574.

86. Baune BT, McAfoose J, Leach G, Quirk F, Mitchell D. Impact of psychiatric and medical comorbidity on cognitive function in depression. Psychiatry Clin Neurosci 2009;63: $392-400$.

87. Kurtz MM, Gerraty RT. A meta-analytic investigation of neurocognitive deficits in bipolar illness: profile and effects of clinical state. Neuropsychology 2009;23:551-562.

88. Austin MP, Ross M, Murray C, O'Carroll RE, Ebmeier KP, Goodwin GM. Cognitive function in major depression. $J$ Affect Disord 1992;25:21-29.

89. Cataldo MG, Nobile M, Lorusso ML, Battaglia M, Molteni M. Impulsivity in depressed children and adolescents: a comparison between behavioral and neuropsychological data. Psychiatry Res 2005;136:123-133.

90. Naismith SL, Hickie IB, Turner K, Little CL, Winter V, Ward PB, et al. Neuropsychological performance in patients with depression is associated with clinical, etiological and genetic risk factors. J Clin Exp Neuropsychol 2003;25:866877.

91. Kyte ZA, Goodyer IM, Sahakian BJ. Selected executive 
skills in adolescents with recent first episode major depression. J Child Psychol Psychiatry 2005;46:995-1005.

92. Degl'Innocenti A, Agren H, Bäckman L. Executive deficits in major depression. Acta Psychiatr Scand 1998;97:182188.

93. Grant MM, Thase ME, Sweeney JA. Cognitive disturbance in outpatient depressed younger adults: evidence of modest impairment. Biol Psychiatry 2001;50:35-43.

94. Brébion G, Smith MJ, Widlocher D. Discrimination and response bias in memory: effects of depression severity and psychomotor retardation. Psychiatry Res 1997;70:95-103.

95. Elliott R, Sahakian BJ, McKay AP, Herrod JJ, Robbins TW, Paykel ES. Neuropsychological impairments in unipolar depression: the influence of perceived failure on subsequent performance. Psychol Med 1996;26:975-989.

96. McDermott LM, Ebmeier KP. A meta-analysis of depression severity and cognitive function. J Affect Disord 2009; 119:1-8.

97. Williams RA, Hagerty BM, Cimprich B, Therrien B, Bay $\mathrm{E}, \mathrm{Oe} \mathrm{H}$. Changes in directed attention and short-term memory in depression. J Psychiatr Res 2000;34:227-238.

98. Pedersen A, Küppers K, Behnken A, Kroker K, Schöning $\mathrm{S}$, Baune BT, et al. Implicit and explicit procedural learning in patients recently remitted from severe major depression. Psychiatry Res 2009;169:1-6.

99. Pier MP, Hulstijn W, Sabbe BG. Differential patterns of psychomotor functioning in unmedicated melancholic and nonmelancholic depressed patients. J Psychiatr Res 2004; 38:425-435.

100. Michopoulos I, Zervas IM, Papakosta VM, Tsaltas E, Papageorgiou C, Manessi T, et al. Set shifting deficits in melancholic vs. non-melancholic depression: preliminary findings. Eur Psychiatry 2006;21:361-363.

101. Austin MP, Mitchell P, Wilhelm K, Parker G, Hickie I, Brodaty $\mathrm{H}$, et al. Cognitive function in depression: a distinct pattern of frontal impairment in melancholia? Psychol Med 1999;29:73-85.

102. Withall A, Harris LM, Cumming SR. A longitudinal study of cognitive function in melancholic and non-melancholic subtypes of major depressive disorder. J Affect Disord 2010;123:150-157.

103. Fleming SK, Blasey C, Schatzberg AF. Neuropsychological correlates of psychotic features in major depressive disorders: a review and meta-analysis. J Psychiatr Res 2004; $38: 27-35$.

104. Bora E, Yücel M, Pantelis C. Cognitive impairment in affective psychoses: a meta-analysis. Schizophr Bull 2010; 36:112-125.

105. Reichenberg A, Harvey PD, Bowie CR, Mojtabai R, Rabinowitz J, Heaton RK, et al. Neuropsychological function and dysfunction in schizophrenia and psychotic affective disorders. Schizophr Bull 2009;35:1022-1029.

106. Zaninotto L, Guglielmo R, Calati R, Ioime L, Camardese $\mathrm{G}$, Janiri $\mathrm{L}$, et al. Cognitive markers of psychotic unipolar depression: a meta-analytic study. J Affect Disord 2015; 174:580-588.

107. Hasselbalch BJ, Knorr U, Hasselbalch SG, Gade A, Kessing LV. The cumulative load of depressive illness is associated with cognitive function in the remitted state of unipolar depressive disorder. Eur Psychiatry 2013;28:349355 .

108. Iosifescu DV, Renshaw PF, Dougherty DD, Lyoo IK, Lee $\mathrm{HK}$, Fraguas R, et al. Major depressive disorder with anger attacks and subcortical MRI white matter hyperintensities. J Nerv Ment Dis 2007;195:175-178.
109. Murrough JW, Iacoviello B, Neumeister A, Charney DS, Iosifescu DV. Cognitive dysfunction in depression: neurocircuitry and new therapeutic strategies. Neurobiol Learn Mem 2011;96:553-563.

110. Awad N, Gagnon M, Messier C. The relationship between impaired glucose tolerance, type 2 diabetes, and cognitive function. J Clin Exp Neuropsychol 2004;26:1044-1080.

111. Cukierman-Yaffe T, Gerstein HC, Williamson JD, Lazar $\mathrm{RM}$, Lovato L, Miller ME, et al; Action to Control Cardiovascular Risk in Diabetes-Memory in Diabetes (ACCORD-MIND) Investigators. Relationship between baseline glycemic control and cognitive function in individuals with type 2 diabetes and other cardiovascular risk factors: the action to control cardiovascular risk in diabetesmemory in diabetes (ACCORD-MIND) trial. Diabetes Care 2009;32:221-226.

112. McIntyre RS, Kenna HA, Nguyen HT, Law CW, Sultan F, Woldeyohannes HO, et al. Brain volume abnormalities and neurocognitive deficits in diabetes mellitus: points of pathophysiological commonality with mood disorders? Adv Ther 2010;27:63-80.

113. Román GC, Sachdev P, Royall DR, Bullock RA, Orgogozo $\mathrm{JM}$, López-Pousa S, et al. Vascular cognitive disorder: a new diagnostic category updating vascular cognitive impairment and vascular dementia. J Neurol Sci 2004;226: 81-87.

114. Sachdev PS, Brodaty H, Valenzuela MJ, Lorentz L, Looi $\mathrm{JC}, \mathrm{Wen} \mathrm{W}$, et al. The neuropsychological profile of vascular cognitive impairment in stroke and TIA patients. Neurology 2004;62:912-919.

115. McClintock SM, Husain MM, Greer TL, Cullum CM. Association between depression severity and neurocognitive function in major depressive disorder: a review and synthesis. Neuropsychology 2010;24:9-34.

116. Kizilbash AH, Vanderploeg RD, Curtiss G. The effects of depression and anxiety on memory performance. Arch Clin Neuropsychol 2002;17:57-67.

117. DeLuca AK, Lenze EJ, Mulsant BH, Butters MA, Karp JF, Dew MA, et al. Comorbid anxiety disorder in late life depression: association with memory decline over four years. Int J Geriatr Psychiatry 2005;20:848-854.

118. Basso MR, Lowery N, Ghormley C, Combs D, Purdie R, Neel J, et al. Comorbid anxiety corresponds with neuropsychological dysfunction in unipolar depression. Cogn Neuropsychiatry 2007;12:437-456.

119. McKinnon MC, Yucel K, Nazarov A, MacQueen GM. $A$ meta-analysis examining clinical predictors of hippocampal volume in patients with major depressive disorder. $J$ Psychiatry Neurosci 2009;34:41-54.

120. Sheline YI, Sanghavi M, Mintun MA, Gado MH. Depression duration but not age predicts hippocampal volume loss in medically healthy women with recurrent major depression. J Neurosci 1999;19:5034-5043.

121. Kessing LV. Cognitive impairment in the euthymic phase of affective disorder. Psychol Med 1998;28:1027-1038.

122. van Gorp WG, Altshuler L, Theberge DC, Wilkins J, Dixon W. Cognitive impairment in euthymic bipolar patients with and without prior alcohol dependence. A preliminary study. Arch Gen Psychiatry 1998;55:41-46.

123. Bhardwaj A, Wilkinson P, Srivastava C, Sharma M. Cognitive deficits in euthymic patients with recurrent depression. J Nerv Ment Dis 2010;198:513-515.

124. Nieuwenhuijsen K, Faber B, Verbeek JH, NeumeyerGromen A, Hees HL, Verhoeven AC, et al. Interventions to improve return to work in depressed people. Cochrane 
Database Syst Rev 2014;12:CD006237.

125. Hees HL, de Vries G, Koeter MW, Schene AH. Adjuvant occupational therapy improves long-term depression recovery and return-to-work in good health in sick-listed employees with major depression: results of a randomised controlled trial. Occup Environ Med 2013;70:252-260.

126. Lerner D, Adler D, Hermann RC, Chang H, Ludman EJ, Greenhill A, et al. Impact of a work-focused intervention on the productivity and symptoms of employees with depression. J Occup Environ Med 2012;54:128-135.

127. Noordik E, van der Klink JJ, Geskus RB, de Boer MR, van Dijk FJ, Nieuwenhuijsen K. Effectiveness of an exposurebased return-to-work program for workers on sick leave due to common mental disorders: a cluster-randomized controlled trial. Scand J Work Environ Health 2013;39: 144-154.

128. Hollinghurst S, Peters TJ, Kaur S, Wiles N, Lewis G, Kessler D. Cost-effectiveness of therapist-delivered online cognitive-behavioural therapy for depression: randomised controlled trial. Br J Psychiatry 2010;197:297-304.

129. McCrone P, Knapp M, Proudfoot J, Ryden C, Cavanagh $\mathrm{K}$, Shapiro DA, et al. Cost-effectiveness of computerised cognitive-behavioural therapy for anxiety and depression in primary care: randomised controlled trial. $\mathrm{Br} J$ Psychiatry 2004; 185:55-62.

130. Bee PE, Bower P, Gilbody S, Lovell K. Improving health and productivity of depressed workers: a pilot randomized controlled trial of telephone cognitive behavioral therapy delivery in workplace settings. Gen Hosp Psychiatry 2010;32:337-340.

131. Elgamal S, McKinnon MC, Ramakrishnan K, Joffe RT, MacQueen G. Successful computer-assisted cognitive remediation therapy in patients with unipolar depression: a proof of principle study. Psychol Med 2007;37:1229-1238.

132. Siegle GJ, Ghinassi F, Thase ME. Neurobehavioral therapies in the 21st century: Summary of an emerging field and an extended example of cognitive control training for depression. Cognit Ther Res 2007;31:235-262.

133. Papageorgiou C, Wells A. Treatment of recurrent major depression with attention training. Cognit Behav Pract 2000;7:407-413.

134. Lee RS, Redoblado-Hodge MA, Naismith SL, Hermens DF, Porter MA, Hickie IB. Cognitive remediation improves memory and psychosocial functioning in first-episode psychiatric out-patients. Psychol Med 2013;43:1161-1173.

135. Bowie CR, Gupta M, Holshausen K, Jokic R, Best M, Milev R. Cognitive remediation for treatment-resistant depression: effects on cognition and functioning and the role of online homework. J Nerv Ment Dis 2013;201:680-685.

136. Wade AG, Fernández JL, François $C$, Hansen $K$, Danchenko N, Despiegel N. Escitalopram and duloxetine in major depressive disorder: a pharmacoeconomic comparison using UK cost data. Pharmacoeconomics 2008;26: 969-981.

137. Romeo R, Patel A, Knapp M, Thomas C. The costeffectiveness of mirtazapine versus paroxetine in treating people with depression in primary care. Int Clin Psychopharmacol 2004;19:125-134.

138. Fernandez JL, Montgomery S, Francois C. Evaluation of the cost effectiveness of escitalopram versus venlafaxine XR in major depressive disorder. Pharmacoeconomics 2005; 23:155-167.

139. Naismith SL, Redoblado-Hodge MA, Lewis SJ, Scott EM, Hickie IB. Cognitive training in affective disorders improves memory: a preliminary study using the NEAR approach. $J$ Affect Disord 2010;121:258-262.

140. Naismith SL, Diamond K, Carter PE, Norrie LM, RedobladoHodge MA, Lewis SJ, et al. Enhancing memory in late-life depression: the effects of a combined psychoeducation and cognitive training program. Am J Geriatr Psychiatry 2011; 19:240-248. 